\title{
Constraints Faced by the Paddy Growers in Adoption of Recommended Paddy Production Practices in Budgam District of Kashmir, India
}

\author{
Jehangir Muzaffar Matto*, Mushtaq Ahmad Dar, Zahoor Ahmad Shah, \\ Mohmad Afzal Beigh and Rufaida Mir
}

\author{
Sher-e Kashmir University of Agricultural Science and Technology of Kashmir, \\ Shalimar, Jammu and Kashmir - 190 025, India \\ *Corresponding author
}

\begin{tabular}{|c|c|}
\hline \multicolumn{2}{|r|}{ A B S T R A C T } \\
\hline & \multirow{6}{*}{$\begin{array}{l}\text { The present study was conducted in Budgam district of Kashmir to assess the constraints } \\
\text { in adoption of recommended agricultural practices in paddy cultivation which helps to } \\
\text { provide feedback to the stakeholders of the programme for its improvement. A sample of } \\
150 \text { trained farmers and } 50 \text { untrained farmers from two selected blocks and were selected } \\
\text { by purposive cum random sampling technique. The majority of farmers covered under the } \\
\text { ATMA programme were of middle age group, having middle standard qualification, } \\
\text { medium family size ( } 5-8 \text { members) and medium experience in farming (16-25 years). Thus } \\
\text { the total numbers of } 200 \text { paddy growers were selected. Average productivity of paddy crop } \\
\text { in Kashmir is very low and far from the national average yield. By adopting improved and } \\
\text { recommended agricultural practices, the production and productivity can be increased. The } \\
\text { major constraints faced by the farmers in adoption of recommended Paddy Production } \\
\text { Practices were lack of skill in seed treatment }(98.88 \%) \text {, lack of technical advice for seed } \\
\text { storage ( } 93.33 \%) \text {, irregular visits of Agricultural Officers (94.44\%), low rate of Paddy in } \\
\text { local market }(84.44 \%) \text {, high cost of fertilizers }(82.22 \%) \text {, high rate of seeds ( } 72.73 \%) \text { and } \\
\text { inadequate and untimely supply of loans }(80 \%) \text {. }\end{array}$} \\
\hline Keywords & \\
\hline $\begin{array}{l}\text { Paddy, Constraint, } \\
\text { Production } \\
\text { technology, } \\
\text { Kashmir. }\end{array}$ & \\
\hline Article Info & \\
\hline $\begin{array}{l}\text { Accepted: } \\
10 \text { October } 2017 \\
\text { Available Online: } \\
10 \text { December } 2017\end{array}$ & \\
\hline & \\
\hline
\end{tabular}

\section{Introduction}

A major need to the developing countries is to raise the standard of living of the people in general and ruralities in specific. In India, where agriculture occupies a dominant position in the economy of country, economic growth and progress actually depends to a large extent on the improvement of agricultural technology and adoption of agricultural innovations by the farmers. Therefore, it is necessary to change the attitude of the farmers so that they may shift from traditional to modern methods of farming. For this purpose, it is essential to disseminate the useful technical know-how to the millions of farmers.

There has been a significant progress in increasing crop production, productivity and acquiring fair degrees of self-reliance over the last decades. This is mainly attributable to the policies, strategies and programmes adopted by the government and also the intensive efforts made by the state agricultural universities and ICAR institutes to achieve a dynamic response of the farmers (Barath and Pandey, 2005). 
Although, scientific research in agriculture is moving fast and new techniques are being added continuously, so far only 20 per cent of the available technology has been adopted by the farmers that too only among 10 per cent of farming population. It is seen that productivity levels of different crops are very low. In order to increase the crop yields, the level of adoption of improved farm practices has to be enhanced. Knowledge of the recommended technologies is a pre-requisite to the adoption process. The basic input for achieving higher productivity in the assimilation of technological knowledge is one of the important components of behaviour and as such it plays a major role in covert and overt behaviour of human beings. Knowledge of the technology is the basic requirement as it gives impetus to adopt technology. The adoption of any technologies depends on the individual development and acceptance of modern agricultural technology is the prime attention for increasing crop production. It is generally observed that all the farmers do not use recommended practices. It is the experience of the extension workers that many practices including plant protection measures in spite of their merits are not accepted widely by the farmers. Some technologies record very slow rate of adoption. It is therefore, a question as to why one practice is more readily adopted than the other. One of the possible answers is some innate characteristics of the practice, which may speed up or retard its rate of adoption. The differential rate of adoption of farm technologies by the farmers is generally attributed to some of the personal and socioeconomic characteristics of farmers (Awotide et al., 2016).

\section{Materials and Methods}

Impact assessment was conducted in district Budgam of Jammu and Kashmir to find out the Constraints faced by the farmers in adoption of recommended Paddy Production Practices and the suggestions for improvement under ATMA. District Budgam comprises of 8 blocks where the ATMA programme was launched in the year 2005-06. Two blocks i.e., Block Budgam and Block Chadoora were selected purposively as having more number of Paddy growers and occupy more area under Paddy. Also more number of farmers has undergone different trainings under ATMA as compared to other blocks of the district. As indicated in Table 1, there were 340 farmers in block Budgam and 410 in Block Chadoora who had attended trainings under ATMA. Out of these farmers a sample of 150 farmers i.e., 68 farmers from Budgam and 82 farmers from Chadoora were randomly selected on the basis of proportional allocation and addition to this, a list of untrained farmers from the same villages was prepared and a sample of 50 farmers was selected randomly. The climate is of temperate type with the upper-reaches receiving heavy snowfall in winter.

The average annual rainfall of the district is $585 \mathrm{~mm}$. Literacy rate is $57.98 \%$. With a predominately rural outlook, $86 \%$ of the population in the district lives in its villages and are primarily involved in agricultural operations. Gender ratio of the district is $833 / 1000$. The study was conducted through pre-tested and semi-structured Interview Schedule. Sample units were selected through multi-stage stratified random sampling method. In this way the research schedule was constructed to collect the necessary information. Interview Schedule Part A. It consists of two parts. Part I dealt with the profile of farmers trained under ATMA. In part II of the Schedule, questions related to Knowledge of recommended Paddy Production Practices were included. The data collected was processed, quantified, categorized and tabulated. The established parameters like mean, frequency, percentage 
and Karl Pearson's product movement correlation coefficient were calculated.

\section{Results and Discussion}

The present investigation attempt was to categories the major constraints viz. technological, resource, market and miscellaneous constraints faced by farmers in paddy production technology.

\section{Economic constraints}

A close examination of Table 2 revealed that among the economic constraints, majority of the farmers from block Budgam experienced the constraints of high rate of interest on loans $(81.82 \%)$ ranking at number I, high rate of seeds $(72.73 \%)$ ranking at number II and inadequacy of capital for purchase of seeds and fertilizers $(69.09 \%)$ ranking at number III followed by high cost of fertilizers $(67.27 \%)$ and high charges of labour $(57.27 \%)$ ranking at number IV and $\mathrm{V}$ respectively. A majority of farmers from block Chadoora reported that among the economic constraints, the main problem faced by them was high cost of fertilizers $(82.22 \%)$ ranking at number I, high rate of seeds $(72.22 \%)$ ranking at number II and inadequacy of capital for purchase of seeds and fertilizers $(68.89 \%)$ ranking at number III. Other economic constraints observed by the farmers of block Chadoora were high rate of interest on loans $(66.66 \%)$ and high charges of labour $(61.11 \%)$ ranking at number IV and $\mathrm{V}$ respectively.

Among the economic constraints, more than seventy per cent of the farmers from block Budgam experienced the constraints of high rate of interest on loans and high rate of seeds while as, more than sixty per cent of the farmers experienced inadequacy of capital for purchase of seeds and fertilizers and high cost of fertilizers as major constraints. Also high charges of labour were experienced by more than fifty per cent of the farmers. In block Chadoora, among the economic constraints, the main problem faced by one third of the farmers was high cost of fertilizers, high rate of seeds and inadequacy of capital for purchase of seeds and fertilizers. Other economic constraints reported by the farmers of block Chadoora were high rate of interest on loans $(66.66 \%)$ and high charges of labour $(61.11 \%)$. Therefore, the availability of financial resources is an important aspect in adopting the recommended Paddy Production Practices because majority of farmers expressed their difficulty regarding availability of finance.

\section{Supply constraints}

It reveals that majority of farmers $(61.82 \%)$ from block Budgam face the problem of inadequate and untimely supply of loans to farmers followed by non-availability of proper irrigation facilities $(41.82 \%)$ ranking at number I and II respectively. More than forty (40.91\%) per cent of the farmers face the problem of non-availability of fertilizers at the time of sowing ranking at number III followed by non-availability of labour at the time of transplanting and harvesting (38.18\%) and non-availability of seeds at the time of sowing in nearby area $(35.45 \%)$ ranking at number IV and $\mathrm{V}$ respectively. In block Chadoora eighty per cent of the farmers reported that inadequate and untimely supply of loans was the major supply constraint ranking at number I, while as, 67.77 per cent of the farmers faced the problem of nonavailability of labour at the time of transplanting and harvesting ranking at number II. The constraints of non-availability of proper irrigation facilities and nonavailability of seeds at the time of sowing in nearby area was faced by 62.22 per cent and 45.55 per cent farmers ranking at number III and IV respectively. Only 35.55 per cent of the farmers faced the constraint of non- 
availability of fertilizers at the time of sowing ranking at number $\mathrm{V}$.

It was seen that more than sixty per cent of farmers from block Budgam face the problem of inadequate and untimely supply of loans to farmers followed by non-availability of proper irrigation facilities $(41.82 \%)$. More than forty per cent of the farmers face the problem of non-availability of fertilizers at the time of sowing followed by nonavailability of labour at the time of transplanting and harvesting (38.18\%) and non-availability of seeds at the time of sowing in nearby area $(35.45 \%)$. In block Chadoora, eighty per cent of the farmers stated that inadequate and untimely supply of loans was the major supply constraint while as, 67.77 per cent of the farmers faced the problem of non-availability of labour at the time of transplanting and harvesting. The constraints of non-availability of proper irrigation facilities and non-availability of seeds at the time of sowing in nearby area were faced by 62.22 per cent and 45.55 per cent of the farmers respectively. A minimum percentage $(35.55 \%)$ of the farmers faced the constraint of non-availability of fertilizers at the time of sowing. The success of crop production depends on the full time of labour and timely availability of seeds and fertilizer for adoption of the recommended Paddy Production Practices.

\section{Marketing constraints}

Table 2 indicates that among the marketing constraints, a majority of the farmers (83.64\%) from block Budgam expressed that the main constraint faced by them was low rate of Paddy in the local market ranking at number I followed by non-availability of stores in nearby area $(78.18 \%)$ ranking at number II. The other marketing constraints expressed by the farmers of block Budgam were lack of co-operative societies for the purchase of produce $(72.73 \%)$, poor transport facility in rural areas $(29.09 \%)$ and delay in payment of purchase $(27.27 \%)$ ranking at number III, IV and V respectively. Majority of the farmers $(84.44 \%)$ from block Chadoora faced the main problem of low rate of Paddy in local market and lack of co-operative societies for the purchase of produce (76.67\%) ranking at number I and II. The other marketing constraints faced by the farmers include delay in payment of purchase (71.11\%), non-availability of stores in nearby area $(32.22 \%)$ and poor transport facility in rural areas $(27.77 \%)$ ranking at number III, IV and $\mathrm{V}$ respectively.

Among the marketing constraints, more than eighty per cent of the farmers from block Budgam expressed that the main constraint faced by them was low rate of Paddy in the local market followed by non-availability of stores in nearby area $(78.18 \%)$. The other marketing constraints expressed by the farmers of block Budgam were lack of cooperative societies for the purchase of produce $(72.73 \%)$, poor transport facility in rural areas $(29.09 \%)$ and delay in payments of purchase $(27.27 \%)$ while as, more than eighty per cent of the farmers from block Chadoora faced the main problem of low rate of Paddy in local market and lack of co-operative societies for the purchase of produce (76.67\%). The other marketing constraints faced by the farmers included delay in payments of purchase (71.11\%), nonavailability of stores in nearby area $(32.22 \%)$ and poor transport facility in rural areas $(27.77 \%)$. The problems expressed by the farmers hinder the farmers to adopt the recommended Paddy Production Practices.

\section{Technical constraints}

The data in Table 2 also provides information regarding the technical constraints faced by the farmers in adoption of Paddy Production 
Practices. Among the farmers from block Budgam, a large majority $(90.91 \%)$ faced the problem of lack of skill in seed treatment ranking at number I, followed by 90.00 per cent of the farmers having lack of technical advice for seed storage ranking at number II.

Irregular visits of Agriculture Officers (89.09\%), lack of knowledge about improved seeds $(82.73 \%)$ and seeds available are of sub-standard $(40.91 \%)$ were other technical constraints faced by the farmers ranking at number III, IV and V respectively. In block Chadoora, lack of skill in seed treatment was the major constraint faced by 98.88 per cent of the farmers followed by lack of knowledge about improved seeds (96.66\%) ranking at number I and II respectively. Irregular visits of Agriculture Officers (94.44\%), lack of technical advice for seed storage (93.33\%), and seeds available are of sub-standard $(38.88 \%)$ were the other constraints faced by the farmers of block Chadoora ranking at number III, IV and V respectively.

It was observed that among the farmers from block Budgam, more than ninety per cent faced the problem of lack of skill in seed treatment and lack of technical advice for seed storage. Also, more than eighty per cent of the farmers faced the problems of irregular visits of Agriculture Officers and lack of knowledge about improved seeds while as, seeds available were of sub-standard $(40.91 \%)$ were other technical constraints stated by the farmers. In block Chadoora, more than ninety per cent of the farmers faced the problems of lack of skill in seed treatment, lack of knowledge about improved seeds, irregular visits of Agriculture Officers and lack of technical advice for seed storage. Also more than one fourth of the farmers faced the problem of seeds available are of substandard.

\section{Constraints faced by the farmers in adoption of recommended paddy production practices}

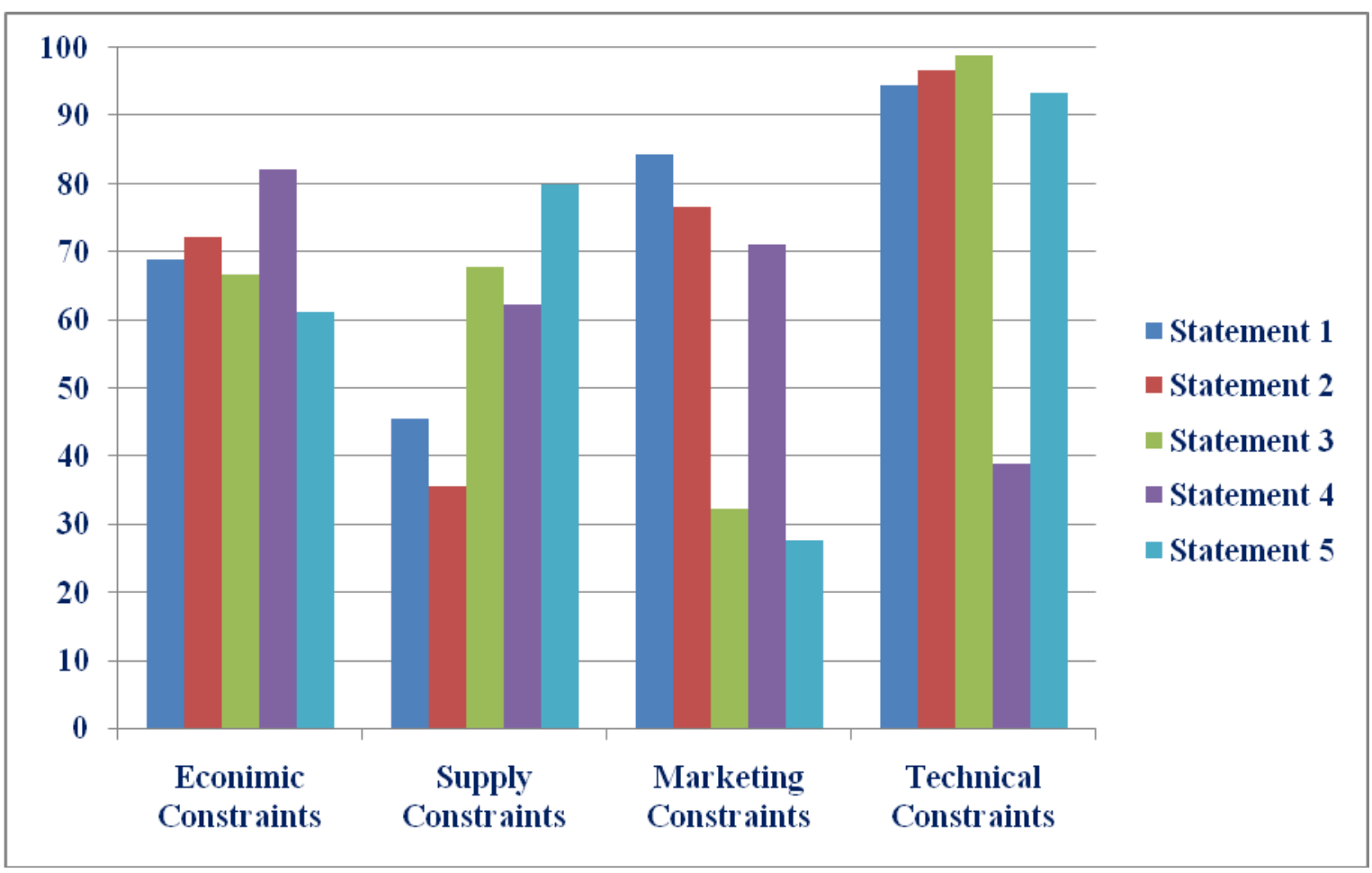

Budgam 


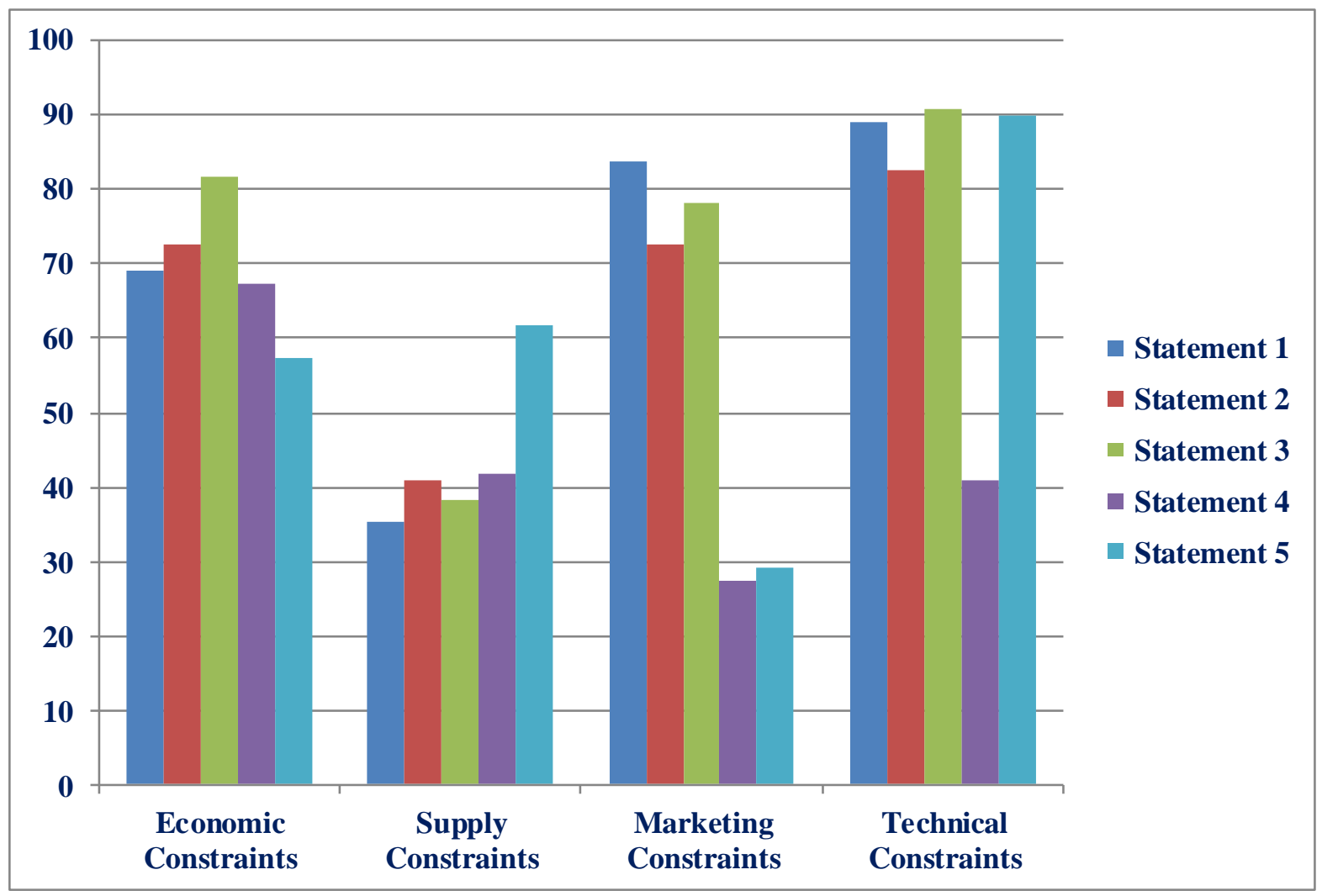

\section{Chadoora}

Table.1 Distribution of farmers under ATMA

\begin{tabular}{|c|c|c|}
\hline District & \multirow{2}{*}{\multicolumn{2}{|c|}{$\begin{array}{l}\text { No. of Blocks in District Budgam } \\
8 \text { (Budgam, Beerwah, Chodoora, Khansahib, Khag, } \\
\text { B.K.Pora, Narbal and Nagam) }\end{array}$}} \\
\hline No. of B locks in District Budgam & & \\
\hline No. of Blocks selected for the study & \multicolumn{2}{|c|}{$2($ B udgam, Chadoora $)$} \\
\hline \multirow[t]{2}{*}{ Total number of farmers attended training under ATMA } & $\begin{array}{l}\text { B } 1 \text { o } \quad \text { c } k \\
\text { Budgam }\end{array}$ & $\begin{array}{lllll}\text { B } & 1 & \text { o } & \text { c } & k \\
\text { Chadoora } & & & \end{array}$ \\
\hline & 4 & 4 \\
\hline \multirow[t]{2}{*}{$\begin{array}{l}\text { No. of trained farmers selected for data collection } \\
(@ 20 \%)\end{array}$} & $\begin{array}{l}\text { B } 1 \text { o c } \mathrm{k} \\
\text { Budgam }\end{array}$ & $\begin{array}{lllll}\text { B } & 1 & \text { o } & \text { c } & \text { k } \\
\text { Chadoora } & & & & \end{array}$ \\
\hline & & 6 \\
\hline No. of Un-trained farmers selected for data collection & & 2 \\
\hline $\mathrm{No}$. of B locks in District Budgam & \multicolumn{2}{|c|}{15} \\
\hline Tota l no. of $\mathrm{Un}-\mathrm{t}$ & \multicolumn{2}{|c|}{$\begin{array}{ll}5 & 0\end{array}$} \\
\hline
\end{tabular}


Table. 2 Constraints faced by the farmers in adoption of recommended Paddy Production Practices

\begin{tabular}{|c|c|c|c|c|c|c|c|c|c|}
\hline \multirow{2}{*}{\multicolumn{2}{|c|}{ 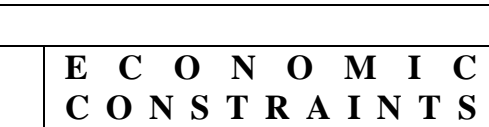 }} & \multicolumn{4}{|c|}{ Budgam $(n=110)$} & \multicolumn{4}{|c|}{ C hadoora $(n=90$} \\
\hline & & \multicolumn{2}{|c|}{ Frequency } & Percentage $*$ & Rank & Frequency & \multicolumn{2}{|c|}{ Percentage $*$} & Rank \\
\hline 1 & Inadequacy of capital for purchase of seeds and fertilizers & 7 & 6 & $\begin{array}{lllll}6 & 9 & 0 & 0 & 9 \\
\end{array}$ & I I I & 6 & 68 & .89 & I I I \\
\hline 2 & $\mathrm{High}$ rate of seeds & 8 & 0 & 72.73 & & 5 & 72 & . 22 & \\
\hline 3 & High rate of interest on loans & 9 & 0 & 81.82 & I & 0 & $\begin{array}{ll}6 & 6\end{array}$ & .66 & \\
\hline 4 & High cost of fertilizers & 7 & 4 & 67.27 & $\mathrm{~V}$ & 4 & 82 & . 22 & $\mathrm{I}$ \\
\hline 5 & High charges of labour & 6 & 3 & 57.27 & $\mathrm{~V}$ & 5 & $\begin{array}{ll}6 & 1 \\
\end{array}$ & . 11 & $\mathrm{~V}$ \\
\hline & 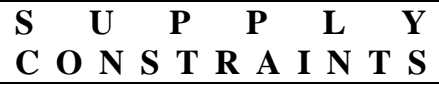 & & & & & & & & \\
\hline 1 & Non-availability of seeds at the time of sowing in nearby area & 3 & 9 & 35.45 & $\mathrm{~V}$ & 1 & 45 & .55 & \\
\hline 2 & Non-availability of fertilizers at the time of sowing & 4 & 5 & $\begin{array}{lllll}4 & 0 & . & 9 & 1 \\
\end{array}$ & I I I I & 2 & 35 & .55 & $\mathrm{~V}$ \\
\hline 3 & Non-avalability of labour a t the time of transplanting and harvesting & 4 & 2 & $\begin{array}{lllll}3 & 8 & . & 1 & 8 \\
\end{array}$ & & 1 & 67 & . 77 & \\
\hline 4 & Non-availability of proper irrigation facilities & 4 & 6 & $\begin{array}{lllll}4 & 1 & . & 8 & 2 \\
\end{array}$ & & 6 & 62 & . 22 & I I I I \\
\hline 5 & Inadequate and untimely supply of loans to farmers & 6 & 8 & $\begin{array}{lllll}6 & 1 & 8 & 8 & 2 \\
\end{array}$ & $\mathrm{I}$ & 2 & 80 & . 000 & $\mathrm{I}$ \\
\hline & $\begin{array}{lllllllllll}M & A & R & K & E & T & I & N & G \\
C & O & N & S & T & R & A & I & N & T & S\end{array}$ & & & & & & & & \\
\hline 1 & Low rate of Paddy in the local market & 9 & 2 & $83 \quad 3 \quad 6 \quad 4$ & $\mathrm{I}$ & 6 & 84 & . 44 & $\mathrm{I}$ \\
\hline 2 & Lack of co-operative societies for the purchase of produce & 8 & 0 & $7 \begin{array}{llll}7 & 2 & 7 & 3 \\
\end{array}$ & I I I & 9 & 76 & .67 & \\
\hline 3 & Non-availability of stores in nearby area & 8 & 6 & $\begin{array}{lllll}7 & 8 & . & 1 & 8\end{array}$ & & 9 & 32 & . 22 & \\
\hline 4 & Delay in payments of purchase & 3 & 0 & 27.27 & $\mathrm{~V}$ & 4 & 71 & . 111 & I 111 \\
\hline 5 & Poor transport facility in rural areas & 3 & 2 & $\begin{array}{lllll}2 & 9 & . & 0 & 9 \\
\end{array}$ & & 5 & 27 & . 77 & $\mathrm{~V}$ \\
\hline & 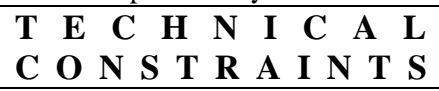 & & & & & & & & \\
\hline 1 & Irregular visits of Agriculture Officers & 9 & 8 & $\begin{array}{lllll}8 & 9 & . & 0 & 9 \\
\end{array}$ & I I I & 4 & 94 & . 44 & I I I \\
\hline 2 & Lack of knowledge about improved seeds & 9 & 1 & $\begin{array}{lllll}8 & 2 & . & 7 & 3 \\
\end{array}$ & $\mathrm{~V}$ & 7 & 96 & .66 & \\
\hline 3 & Lack of skill in seed treatment & 1 & 0 & $\begin{array}{lllll}9 & 0 & . & 9 & 1 \\
\end{array}$ & $\mathrm{I}$ & 9 & 98 & .88 & $\mathrm{I}$ \\
\hline 4 & Seeds available are of sub-standard & 4 & 5 & $\begin{array}{lllll}4 & 0 & . & 9 & 1 \\
\end{array}$ & $\mathrm{~V}$ & 5 & 38 & . 88 & $\mathrm{~V}$ \\
\hline 5 & Lack of technical advice for seed storage & 9 & 9 & $\begin{array}{lllll}9 & 0 & . & 0 & 0\end{array}$ & & 5 & 93 & . 33 & \\
\hline
\end{tabular}

These findings are in conformity with meena et al., (2003), Rai et al., (2013), Ram et al., (2009) and Sahu et al., (2009).

The member farmers had number of problems pertaining to Paddy Production. The important problems pointed out by majority of the farmers were:

High rate of interest on loans in block Budgam (81.82\%) and in block Chadoora $(66.66 \%)$.

High rate of seeds in block Budgam (72.73\%) and in block Chadoora (72.22\%).
Inadequacy of capital for purchase of seeds and fertilizers in block Budgam (69.09\%) and in block Chadoora (68.89\%).

Inadequate and untimely supply of loans to the farmers in block Budgam (61.62\%) and in block Chadoora (80\%).

Non-availability of proper irrigation facilities in block Budgam (41.82\%) and in block Chadoora (62.22\%).

Low rate of Paddy in the local market in block Budgam (83.64\%) and in block Chadoora (84.44\%). 
Non-availability of stores in the nearby area in block Budgam (78.18\%) and in block Chadoora (32.22\%).

Lack of co-operative societies for the purchase of produce in block Budgam $(72.73 \%)$ and in block Chadoora (76.67\%).

Lack of skill in seed treatment in block Budgam (90.91\%) and in block Chadoora (98.88\%).

Lack of technical advice for seed storage in block Budgam (90\%) and in block Chadoora (93.33\%).

\section{Implications}

Based on the findings of the present study, the following implications were drawn:

The findings of the study indicated that only 45.12 per cent of the member farmers from block Budgam and 55.88 per cent of the member farmers from block Chadoora had high level of knowledge about recommended Paddy Production Practices.

Hence it is imperative that State Department of Agriculture, University of Agricultural Sciences and other NGOs should make integrated and concerted extension efforts to provide required knowledge about recommended Paddy Production Practices to the paddy growers.

Majority of the member farmers from block Budgam (52.44\%) and fifty per cent farmers from block Chadoora belonged to low and medium category in adoption of recommended Paddy Production Practices.

Hence, farmers need to be educated and convinced about the importance of recommended Paddy production Practices. So that, their adoption level can be improved.
The findings of the study revealed that lack of technical knowledge was found to be the prime reason among the important reasons for non-adoption of recommended Paddy Production Practices as expressed by the respondents. This poses a real challenge to the extension agencies to increase the knowledge level of farmers through effective capacity building programmes.

The study indicated that though the Paddy is cultivated by many farmers in the study area, their scientific knowledge about the crop and scientific adoption have the gaps. One of the best ways to overcome this is to vigorously utilize the scientific expertise of KVKs (Krishi Vigyan Kendras) for conducting regular off campus training for the farmers. Conducting Farmer's Field Schools would certainly helps to bridge these gaps. Much emphasis thus should be given for such extension approaches by the line departments.

High rate of interest on loans, high cost of fertilizers, inadequate and untimely supply of loans, low rate of Paddy in local market, nonavailability of proper irrigation facilities and lack of skill in seed treatment were the important problems expressed by the farmers that need intervention of researchers and other agencies. Government should ensure that the seeds are made available to the farmers in adequate quantity before the season starts at nearby place to increase the adoption level of recommended Paddy Production Practices.

Publication of folders, leaflets, posters on recommended Production Practices of Paddy and its coverage through radio, television and newspaper is needed to educate farmers and other concerned.

This study revealed that there were no cooperative societies for the purchase of produce. Hence the farmers are to be suggested by extension workers/ personnel to 
form their own marketing society in order to further increase their income and also to improve the standard of living.

It is evident from the study that there was no proper guidance from Agriculture Department, which resulted in low knowledge and adoption of Paddy Production Practices. Hence, there is necessity to organize extension activities in an intensified manner.

\section{References}

Awotide B.A, Karimov A.A. Diagne A.2016. Agricultural technology adoption, commercialization and small holder rice farmers' welfare in rural Nigeria. Agricultural and food economics. 4(3).

Barath, B. C. and Pandey, S. 2005. Rainfed rice production systems in eastern India: An on-farm diagnosis and policy alternatives. Indian J. Agril. Econ, 60(1): 110-136.
Meena, K.C. (2003). Constraints faced by the farmers in adoption of improved cultivation of cabbage in Udaipur district of Rajasthan. Indian Research Journal of Extension Education, 3(2): 69-71.

Rai, D.P. and Singh, Bhupendra (2010). Extent of knowledge and constraints in cotton production technology in Madhya Pradesh. Indian Research Journal of Extension Education. 10(2): 78- 80.

Ram, D., Singh, M.K., Prasad, A., Pradhan, B. and Kumar, M. (2009).Constraints of crop productivity in Sikkim. Agricultural Extension Review. 21(4): 14-16.

Sahu, R.P., Sachan, V.K., Singh, Raman Jeet and Singh, Khilendra (2009). Knowledge gap of farm women in vegetables cultivation. Journal of Communication Studies, 27 (2): 83-87.

\section{How to cite this article:}

Jehangir Muzaffar Matto, Mushtaq Ahmad Dar, Zahoor Ahmad Shah, Mohmad Afzal Beigh and Rufaida Mir. 2017. Constraints Faced by the Paddy Growers in Adoption of Recommended Paddy Production Practices in Budgam District of Kashmir, India. Int.J.Curr.Microbiol.App.Sci. 6(12): 1206-1214. doi: https://doi.org/10.20546/ijcmas.2017.612.137 